\title{
Differential Activity of Carboxylic Acid Amide Fungicides Against Various Developmental Stages of Phytophthora infestans
}

\author{
Yigal Cohen and Ulrich Gisi
}

First author: The Mina \& Everard Goodman Faculty of Life Sciences, Bar-Ilan University, Ramat-Gan, Israel; and second author: Syngenta Crop Protection, Research Biology, Stein CH-4332, Switzerland.

Accepted for publication 24 April 2007.

\begin{abstract}
Cohen, Y., and Gisi, U. 2007. Differential activity of carboxylic acid amide fungicides against various developmental stages of Phytophthora infestans. Phytopathology 97:1274-1283.

Three carboxylic acid amide (CAA) fungicides, mandipropamid (MPD), dimethomorph (DMM) and iprovalicarb (IPRO) were examined for their effects on various asexual developmental stages of Phytophthora infestans in vitro and in planta. Germination of cystospores and direct germination of sporangia were inhibited with nanomole concentrations of MPD $(0.005 \mu \mathrm{g} / \mathrm{ml})$ and micromole concentrations of DMM $(0.05 \mu \mathrm{g} / \mathrm{ml})$ or IPRO $(0.5 \mu \mathrm{g} / \mathrm{ml})$. A temporary exposure of $1 \mathrm{~h}$ to CAAs was not detrimental to germination and infectivity of sporangia or cystospores. CAAs applied to cystospores at $1 \mathrm{~h}$ after the onset of germination did not prevent the emergence of germ tubes, but inhibited their further growth and deformed their shape. None of the fungicides affected discharge of

sporangia and drop inoculated onto detached leaves strongly suppressed infection. Curative application at 1 day postinoculation (dpi) required higher concentrations of CAAs than preventive application to inhibit infection and lost its effectiveness at $2 \mathrm{dpi}$. When sprayed on established late blight lesions 4 days after inoculation, CAAs reduced sporangial production in a dose-dependent manner. Trans-laminar protection of potato or tomato leaves, although achieved with higher doses, was more effective with MPD than with DMM or IPRO. Shade house studies demonstrated superior control of late blight epidemics by MPD compared with the other molecules. The data suggest that germ tube formation by cystospores or sporangia is the most sensitive stage in the life cycle of $P$. infestans to CAAs. Of the three CAAs, MPD had the highest intrinsic activity against spore germination. This property, together with its better trans-laminar activity, makes MPD more effective than DMM or IPRO in controlling epidemics caused by $P$. infestans.
\end{abstract} zoospores from sporangia or the encystment (cell wall formation/ assembly) of the zoospores. Mycelium growth in solid or liquid media was inhibited with micromole concentrations. CAAs mixed with
Additional keywords: disease control, mandelic, oomycetes, valinamid carbamates.
Late blight caused by Phytophthora infestans (Mont.) de Bary is a devastating disease of potato and tomato worldwide. A large number of fungicides, of different chemical classes with different modes of action, are available for the control of oomycete plant pathogens including late blight (5). Among them are phenylamides (RNA synthesis inhibitors, e.g., metalaxyl), heteroaromatics (DNA inhibitors, e.g., etridiazole), dinitroanilines (ATP production inhibitors, e.g., fluazinam), carbamates (affecting membrane permeability, e.g., propamocarb), cyano-acetamide oximes (e.g. cymoxanil, unknown mode of action), quinone outside inhibitor (QoI) and quinone inside inhibitor (QiI) fungicides (respiration inhibitors at complex III, Qo and Qi pocket, respectively, e.g., fenamidone and cyazofamid, respectively), benzamides (inhibitors of $\beta$-tubulin assembly, e.g., zoxamide), CAAs (affecting cell wall assembly, e.g., dimethomorph) and a number of multi-site inhibitors (e.g., copper, mancozeb and chlorothalonil) (5). These fungicides differ in their activity against various developmental stages in the life cycle of Phytophthora spp. For example, mancozeb is effective against zoospore discharge (4), fluazinam and QoIs are effective against zoospore motility (15), dimethomorph against cystospore germination and mycelial growth $(4,16)$, and metalaxyl against mycelial growth and haustoria formation (16).

Mandipropamid (MPD) is a new mandelic acid amide fungicide, which together with dimethomorph (DMM) and flumorph

Corresponding author: Y. Cohen; E-mail address: ycohen@mail.biu.ac.il

doi:10.1094/PHYTO-97-10-1274

(c) 2007 The American Phytopathological Society (cinnamic acid amides), iprovalicarb and benthiavalicarb (valinamid carbamates), belongs to the carboxyl acid amide (CAA) fungicides (information available on the Fungicide Resistance Action Committee [FRAC] website), all effective against oomycete foliar plant pathogens. MPD was recently described by Lamberth et al. (15) as having high anti-oomycete activity (15). Recent field studies indicate $(8,10,11)$ that MPD is highly effective against late blight in potato and tomato, downy mildew in grapes and several downy mildews in vegetable crops. The fungicide was shown (10) to quickly bind to the wax layer of the leaf surface, thus providing strong rain-fastness and long lasting efficacy. A small part of MPD is taken up by the leaf tissue so as to contribute to curative and trans-laminar activities against disease. Microscopical studies (14) showed that MPD was highly effective against cystospore and sporangial germination (but not against zoospore discharge) in vitro as well as against mycelial growth, haustoria formation, and sporulation of $P$. infestans and Plasmopara viticola in their respective hosts, potato and grape. The four CAAs belong to one cross-resistance group, because field isolates of Plasmopara viticola exhibit resistance to all (FRAC website) (6).

Cytological studies $(2,4,12,13,16-18)$ showed that DMM, iprovalicarb, and benthiavalicarb, as well as the experimental CAA XR-539 (22), inhibit cell wall biosynthesis/assembly. This was attributed to the fact that they inhibit sporangial and cystospore germination of various Phytophthora species and cystospore germination of Plasmopara viticola. Albert et al. (2) reported that DMM inhibited all stages in the development cycles of $P$. infestans and Plasmopara viticola except zoosporogenesis, zoospore discharge, and motility. Minimal inhibitory concentrations (MIC) 
for sporangial and cystospore germination ranged between 0.2 to 1.6 and 0.4 to $1.6 \mu \mathrm{g} / \mathrm{ml}$, respectively. DMM applied to infected potato leaf disks 1 day before sporulation caused 88 and $100 \%$ inhibition of sporulation at 75 and $150 \mu \mathrm{g} / \mathrm{ml}$, respectively. These authors concluded that DMM exhibited its fungicidal activity by interference with fungal cell wall morphogenesis. A similar conclusion was reached for iprovalicarb $(13,17)$. Mehl and Buchenauer (17) showed that sporangial germination of $P$. infestans was inhibited with a fifty percent effective dose $\left(\mathrm{ED}_{50}\right)$ of $0.25 \mu \mathrm{g} / \mathrm{ml}$. Jende et al. (13) reported that cystospore germination was inhibited on tomato leaf surfaces treated with iprovalicarb (IPRO) at $5 \mu \mathrm{g} / \mathrm{ml}$. Mycelium treated in vitro altered staining of cell walls with fluorochromes. Biochemical studies (7) with the mandelamide fungicide SX 623509 suggested alterations in phospholipid biosynthesis with an inhibition of phosphatidylcholine (lecithin) biosynthesis as a main target.

The objectives of this study were twofold: to provide data on the sensitivity of $P$. infestans to MPD at various developmental stages of its asexual life cycle in vitro and in planta, and to compare these effects of MPD with the corresponding effects of the two CAA fungicides, (DMM) and (IPRO), which are used commercially for late blight control.

\section{MATERIALS AND METHODS}

Fungicides. Three CAA fungicides were used: MPD (Syngenta, $\mathrm{mw}=412$ ), DMM (BASF, $\mathrm{mw}=266$ ), and IPRO, (Bayer, $\mathrm{mw}=320)$. Technical grade fungicides were dissolved in dimethyl sulfoxide (DMSO) $(10 \mathrm{mg} / \mathrm{ml})$ and diluted in double distilled water (DDW) to the desired concentrations. Formulated fungicides used were MPD 250SC, DMM (Forum) 50\% WP, and IPRO 50\% WG. Technical grade fungicides were used in spore germination assays and mycelium growth in vitro studies. Formulated products were used in spore germination assays, infection of detached leaves, infection of intact plants, curative assays, sporulation assays in detached leaves, trans-laminar efficacy and field trials. All concentrations are represented in units of active ingredient.

Fungal isolates. $P$. infestans isolate 96 (A1 mating type, Syngenta collection) was used in all laboratory and growth chamber studies. Plants in shade house trials were inoculated with a mixture of Israeli field isolates or a mixture of field isolates and F1 hybrid isolates. Plants in the open field were naturally infected. Isolate 96 was grown on rye-dextrose agar (RDA) (150 g of rye seed extract, $10 \mathrm{~g}$ of dextrose, $20 \mathrm{~g}$ of agar in 1 liter of DDW) at $20^{\circ} \mathrm{C}$ whereas the Israeli isolates were maintained by repeated transfers on detached tomato leaves in petri dishes at $12^{\circ} \mathrm{C}, 12 \mathrm{~h}$ light/day.

Plants. Detached leaf assays were done with greenhousegrown, 10- to 11-leaf potato (cv. Bintje) or tomato (cv. Baby) plants. Leaves number four to eight from stem base were usually taken.

Inoculum preparation. For in vitro assays, sporangia were washed off 9- to 12-day-old RDA cultures with ice-cold DDW. Sporangia were collected and washed with DDW on an $8 \mu \mathrm{m}$ Millipore membrane, suspended in DDW, and placed in $5 \mathrm{~cm}$ petri dishes $(6 \mathrm{ml} / \mathrm{dish})$ at $4^{\circ} \mathrm{C}$ for $1 \mathrm{~h}$. Dishes were then placed on the bench $\left(20\right.$ to $22^{\circ} \mathrm{C}$ ) for $0.5 \mathrm{~h}$ to allow for the release of zoospores from sporangia. Zoospores were separated from sporangial shells and sporangia by filtering through Whatman No. 4 filter paper into a vial kept on ice. Zoospores were used as derived, or were vortexed for $30 \mathrm{~s}$ to induce synchronous encystment. Cystospores were kept on ice until used. To increase concentration, cystospore suspensions were centrifuged at 1,300 $\operatorname{rpm}(270 \times g)$ at $4^{\circ} \mathrm{C}$ for $10 \mathrm{~min}$, and the cystospores in the pellet were resuspended in the desired volume of DDW. Sporangia were used without precooling when their direct germination had to be tested.
Fungicide application. Sporangia, zoospores, or cystospores in DDW were mixed in test tubes $(1: 1, \mathrm{vol} / \mathrm{vol})$ with CAAs to final fungicide concentrations of 0.0005 to $5 \mu \mathrm{g} / \mathrm{ml}$ (unless stated otherwise) and used for either in vitro assays or inoculation of detached leaves. In some experiments, detached leaves were sprayed with CAAs (same final concentrations) on their lower surfaces and thereafter spray-inoculated with sporangia on lower surfaces. Application to whole potted plants was done by spraying CAAs ( 0.39 to $100 ; 0.1$ to $500 ; 62.5$ to $1,000 \mu \mathrm{g} / \mathrm{ml}$, depending on the experiment) onto the upper leaf surfaces to run off with the aid of a hand sprayer.

Zoospore release and motility. Droplets $(20 \mu \mathrm{l})$ containing 200 sporangia, CAAs (final concentration ranged between 0.005 and $5 \mu \mathrm{g} / \mathrm{ml}$ for technical CAAs or 0.0005 and $5 \mu \mathrm{g} / \mathrm{ml}$ for formulated CAAs), water, or DMSO (as controls) were applied to depressions in glass slides. Slides were placed on wet filter paper in $(20 \times 20 \times 3) \mathrm{cm}$ dishes, incubated at $4^{\circ} \mathrm{C}$ for $1 \mathrm{~h}$ (to induce zoosporogenesis) and then at $20^{\circ} \mathrm{C}$ for $1 \mathrm{~h}$. The number of empty sporangia and the frequency of motile zoospores were examined with the aid of an interference light microscope at $\times 100$ magnification.

Germination of zoospores, cystospores, and sporangia. Droplets $(20 \mu \mathrm{l})$ containing motile zoospores, cystospores, or sporangia and CAAs (final concentration ranged between 0.005 and $5 \mu \mathrm{g} / \mathrm{ml}$ for technical CAAs and 0.0005 and $5 \mu \mathrm{g} / \mathrm{ml}$ for formulated CAAs), water, or DMSO (as controls) were applied to depressions in glass slides. Slides were placed on wet filter paper in $(20 \times 20 \times 3 \mathrm{~cm})$ dishes and incubated at $20^{\circ} \mathrm{C}$ (unless stated otherwise) in the dark for 4 to $5 \mathrm{~h}$ (zoospores and cystospores) or $20 \mathrm{~h}$ (sporangia) and then examined with an interference light microscope at $\times 100$ to $\times 400$ magnification. The percentage of germinating cells was counted and their germ tube length measured.

Effect on germinating sporangia and cystospores. Sporangia or cystospores were mixed with CAAs of various concentrations as above and kept on the bench for up to $1 \mathrm{~h}$. Cells were thereafter washed with DDW over a Millipore membrane ( 8 or $0.45 \mu \mathrm{m}$ pore size for sporangia or cystospores, respectively), resuspended in DDW and applied to depressions in glass slides for observing germination or to detached potato leaves to test their infectivity as described below.

Alternatively, cystospores in suspension were applied to depressions in glass slides $(10 \mu \mathrm{l}$ containing about 500 cystospores/ depression) and incubated at $20^{\circ} \mathrm{C}$ in the dark. CAAs were added (10 $\mu \mathrm{l} /$ depression) at 0,1 , or $2 \mathrm{~h}$ when $0,0.5$, and $45 \%$ of the cystospores have already germinated, respectively. After a total of $4 \mathrm{~h}$, cystospores were examined microscopically for percent germination and germ tube length.

Mycelial growth in vitro. A 5-mm agar plug carrying mycelium of $P$. infestans was adhered to the bottom of each well in 6 well plates, and $1.8 \mathrm{ml}$ of liquid rye medium $(60 \mathrm{~g}$ of rye seed extract, $20 \mathrm{~g}$ of D-glucose, and $2 \mathrm{~g}$ of yeast extract per liter of DDW) and $0.2 \mathrm{ml}$ of DDW (control) or technical CAA (final concentrations $0.005,0.01,0.05,0.1,0.5,1,5$, and $10 \mu \mathrm{g} / \mathrm{ml}$, or DDW as control) was added to each well. After 10 days of incubation at $20^{\circ} \mathrm{C}$ in the dark, the colonies developed on liquid medium were removed, blotted dry, and their fresh weight was taken.

Growth inhibition in solid medium was done in 9-cm petri dishes. Technical CAAs were dissolved in DMSO and added to molten RDA (about $50^{\circ} \mathrm{C}$ ) after autoclaving (final concentrations: $0.005,0.01,0.05,0.1,0.5,1,5$, and $10 \mu \mathrm{g} / \mathrm{ml}$ ). A 5-mm agar plug carrying mycelium of $P$. infestans was adhered to the center of the medium. After 10 days of incubation at $20^{\circ} \mathrm{C}$ in the dark, the radius of the colonies was measured from the edge of the inoculum plug.

Temporary exposure of mycelia was done as follows: 5-mm agar plugs carrying mycelium were taken from the edge of RDA cultures of $P$. infestans (11 days old) and placed in a tube con- 
taining CAA of 1,10 , or $100 \mu \mathrm{g} / \mathrm{ml}$ or DDW as control (5 plugs/ $2 \mathrm{ml}$ ). At 0, 30, 60, and $90 \mathrm{~min}$, plugs were removed, washed with sterile DDW, and placed on fresh RDA in $9 \mathrm{~cm}$ petri dishes. Colony diameter was measured after 7 days of incubation at $20^{\circ} \mathrm{C}$ in the dark and percent growth inhibition relative to water control was calculated.

Infection of detached leaves. Leaves having five leaflets were placed on wet filter paper, lower surface uppermost, in Nunk dishes. Potato leaflets were each inoculated with four (proximal leaflets) or eight (distal leaflets) $10-\mu \mathrm{l}$ droplets of a mixture (1:1) of inoculum suspension and a CAA fungicide. Tomato leaflets were each inoculated with $10,20-\mu$ l droplets of such mixtures. Dishes were incubated at $20^{\circ} \mathrm{C}$ in the dark for $20 \mathrm{~h}$ and thereafter exposed to $12 \mathrm{~h}$ light/day. Percent leaf area occupied with mycelium and sporangia of $P$. infestans was visually assessed, or the number of sporulating late blight lesions/leaflet was determined at $7 \mathrm{dpi}$. In other experiments, leaf disks of $24 \mathrm{~mm}$ in diameter, each harboring a single late blight lesion $(\approx 1 \mathrm{~cm}$ in diameter), were taken from tomato plants and placed, lower surface up, on moist filter paper in petri dishes. Twenty-five $10-\mu l$ droplets containing formulated fungicides $(100 \mu \mathrm{g} / \mathrm{ml})$, were placed on each leaf disk, 10 on the lesion and 15 around the lesion. After 3 days of incubation at $20^{\circ} \mathrm{C}$, the number of sporangia produced was determined.

Infection of whole plants. Potato or tomato plants were sprayed with CAAs $(0.39,1.56,6.25,25$, and $100 \mu \mathrm{g} / \mathrm{ml})$ on upper leaf surfaces and $4 \mathrm{~h}$ later, when spray droplets have dried up, were inoculated with sporangial suspension $(5,000$ sporangia/ml $)$ on upper, CAA-treated leaf surfaces. Inoculated plants were placed in a dew chamber at $18^{\circ} \mathrm{C}$ in the dark for $20 \mathrm{~h}$ to assure infection and thereafter incubated in a $20^{\circ} \mathrm{C}$ growth chamber $(12 \mathrm{~h}$ light/ day, 60 to $70 \%$ relative humidity [RH]) for symptom production. Percentage of blighted leaf area was recorded at $7 \mathrm{dpi}$.

Postinfection activity. Detached potato or tomato leaves in moistened Nunk dishes were each inoculated with eight $10-\mu \mathrm{l}$ droplets of sporangial suspension and incubated in the dark to assure infection. At $24 \mathrm{~h}$ after inoculation, a 20- $\mu$ ldroplet of CAA (or DDW as control) was applied on top of each inoculum droplet. The treated leaves were incubated in a growth chamber at $20^{\circ} \mathrm{C}$ as above. Sporangial production was used as a measure to estimate infection: at 4 dpi leaflets were placed in $5 \mathrm{ml}$ of $50 \%$ ethanol and shaken for $10 \mathrm{~min}$ at $100 \mathrm{rpm}$ and the number of sporangia produced was counted with aid of a hemacytometer (four counts per leaflet).

Effect on sporulation. Tomato plants were inoculated with $20-\mu \mathrm{l}$ droplets of sporangial suspension placed in the center of the upper leaf surface, one drop per leaflet. Plants were kept in a dew chamber for $20 \mathrm{~h}$ and then transferred to a $20^{\circ} \mathrm{C}$ growth chamber with $12 \mathrm{~h}$ light/day and 60 to $70 \% \mathrm{RH}$. At 3 or 4 dpi when late blight lesions appeared (about 0.7 or $1 \mathrm{~cm}$ in diameter, respectively), leaflets (carrying a single lesion each) were detached, placed lower surface uppermost in moistened Nunk dishes, and sprayed with CAAs of various concentrations. Dishes were incubated at $20^{\circ} \mathrm{C}(12 \mathrm{~h} /$ day $)$ for 2 days to allow for sporulation of the pathogen. Leaflets were then placed in vials containing $5 \mathrm{ml}$ of $50 \%$ ethanol and shaken for $10 \mathrm{~min}$ at $100 \mathrm{rpm}$ and the number of sporangia produced was counted with aid of a hemacytometer (four counts per leaflet).

Trans-laminar activity. Potato or tomato plants were sprayed with CAAs of 62.5 to $1,000 \mu \mathrm{g} / \mathrm{ml}$ (or water) on the upper leaf surfaces $(10 \mathrm{ml} /$ plant) and spray droplets were allowed to dry up in a ventilated hood for 4 to $5 \mathrm{~h}$. Leaves were then detached and placed with the opposite, lower surface uppermost, in Nunk dishes on moist filter paper. Tomato leaves were inoculated with $10-\mu \mathrm{l}$ droplets of sporangial suspension, 4 droplets per leaflet, and the number of sporulating lesions was counted at $7 \mathrm{dpi}$. Potato leaves were spray-inoculated with precooled sporangial suspension $\left(1 \times 10^{4}\right.$ sporangia/ml $)$. The percentage of infected leaf area was recorded at $7 \mathrm{dpi}$.
Statistical analyses. Laboratory and growth chamber experiments were performed twice. The experimental design in germination assays in vitro consisted of three replicates per fungicide per dose, with 100 cystospores or 200 sporangia examined per replicate (unless stated otherwise). Mycelium growth assays in vitro were performed with six replicates per fungicide per dose. Experiments with leaf disks, detached leaves or intact plants were performed with five or six replicates per fungicide per dose. Data from repeated experiments were combined for analysis because variances between experiments were homogenous. $\mathrm{ED}_{50}$ values, with $95 \%$ confidence interval, were calculated after $\log _{10}$ transformation of the data by using the PROBIT procedure of the statistical analysis system (SAS) (version 6; 4th Edition, SAS Institute Inc., Cary, NC, 1990). Analysis of variance was employed to determine significant differences among treatments. Means were separated by Fisher's protected leaf significance difference (LSD) test $(P=0.05)$.

Disease control in shade houses. Two experiments were conducted with potato, the first during December 2005 to March 2006 with cv. Dita and the second during December 2006 to March 2007 with cv. Nicola. Both experiments were performed in shade houses $(15 \times 20 \mathrm{~m})$ located at Bar-Ilan University farm. Houses were covered with white 50 mesh antivirus plastic nets to avoid virus transmission by aphids. Plants (six plants per $1 \mathrm{~m}$ ) were first treated with CAAs at 6 weeks after planting when plants reached approximately 100 leaflets/plant. Each CAA (MPD, DMM, and IPRO) was applied at a dose of 300, 150, or $75 \mathrm{~g}$ a.i./ha (representing $\times 2, \times 1$, and $\times 0.5$ of the field rate) with a motorized backpack sprayer. At $8 \mathrm{~h}$ after the first spray (at $17 \mathrm{~h}$ ) plants were spray-inoculated with a sporangial suspension $(1,000$ sporangia/ml) composed of a mixture of 165 isolates of $P$. infestans, 0.5 liter per row by using a manual backpack sprayer. The same isolate mixture was used in both experiments. It contained 75 field isolates and $90 \mathrm{~F} 1$ hybrid isolates. The field isolates were collected from potato or tomato fields in Israel and included A1 and A2 isolates, metalaxyl sensitive and resistant isolates, and isolates with simple or complex race structure (3). The F1 hybrids were produced by crossing Israeli field isolates (19). Isolates were maintained on detached tomato leaves in a $12^{\circ} \mathrm{C}$ growth chamber by repeated inoculations. Sporangia were collected by washing the leaves into ice-cooled DDW, and their concentration was adjusted with the aid of a hemacytometer. After inoculation, plants were covered for the night with plastic sheets to ensure infection. Sprays with CAAs were repeated at 7- to 8-day intervals for a total of four applications. Day/night temperatures during the experimental periods ranged between 15 to $24^{\circ} \mathrm{C} / 7$ to $12^{\circ} \mathrm{C}$ in the first experiment and 13 to $23^{\circ} \mathrm{C} / 6$ to $11^{\circ} \mathrm{C}$ in the second experiment. Total precipitation for each experiment ranged between 100 and $120 \mathrm{~mm}$, respectively. When necessary, plants were irrigated by drip irrigation. The number of infected leaflets in each row was counted at 3-to 5-day intervals over a period of 44 and 57 dpi in the first and the second experiment, respectively. Percentage blighted leaflets in the control and treatment rows during the season were used to calculate the area under disease progress curve (AUDPC). Percent inhibition of AUDPC in each experiment was calculated as 100[1 - (AUDPC treatment/AUDPC control)]. Analysis of variance was used to compare fungicide efficacy and to determine significant differences among treatments. Means were separated by Fisher's protected LSD test $(P=0.05)$. AUDPC values were subjected to the PROBIT procedure after $\log _{10}$ transformation of the data to calculate $\mathrm{ED}_{50}$ of each CAA in each experiment.

\section{RESULTS}

Zoospore release and motility. CAAs of up to $5 \mu \mathrm{g} / \mathrm{ml}$ had no significant effect on the discharge of zoospores from sporangia relative to the appropriate controls. The mean number of empty 
sporangia ranged between 70 and $80 \%$ in both the controls and the CAAs treatments, and abundant motile zoospores were observed in the controls and the CAAs treatments. CAAs did not affect the speed of zoospores movement. While zoospores in the controls stopped moving after 2 to $3 \mathrm{~h}$, some zoospores in CAAs remained motile after $24 \mathrm{~h}$.

Sporangia that were subjected to CAAs (up to $5 \mu \mathrm{g} / \mathrm{ml}$, highest tested) at 20 to $22^{\circ} \mathrm{C}$ for $20 \mathrm{~h}$ (to allow for direct germination) and thereafter transferred to $4^{\circ} \mathrm{C}$ produced many motile zoospores within $3 \mathrm{~h}$. These zoospores emerged from the nongerminating sporangia which survived the CAAs treatments. Evans Blue staining of CAA-treated sporangia produced no blue color inside the sporangia, whereas heat-treated sporangia did stain, indicating that CAAs caused no damage to the sporangial outer membrane.

Zoospore encystment. CAAs added to motile zoospores did not interfere with their encystment (cell wall formation and/or assembly). However, germination of the encysted zoospores was strongly inhibited. Formulated MPD caused 71 and $100 \%$ inhibition at 0.0005 and $0.005 \mu \mathrm{g} / \mathrm{ml}$, respectively. DMM and IPRO of $0.0005,0.005,0.05$, and $0.5 \mu \mathrm{g} / \mathrm{ml}$ induced $17,45,80,100$, and $12,18,25$, and $100 \%$ inhibition of cystospore germination, respectively. $\mathrm{ED}_{50}$ values derived from these figures (doses at which $50 \%$ of the cystospores did not germinate) were $<0.0005,0.025$, and $0.1 \mu \mathrm{g} / \mathrm{ml}$ for MPD, DMM, and IPRO, respectively.

Cystospores that failed to germinate in CAAs were swollen, reaching a diameter of 7 to $8 \mu \mathrm{m}$ compared with 5 to $6 \mu \mathrm{m}$ of germinating ones. Cystospore that did not germinate in water had a diameter of 4 to $5 \mu \mathrm{m}$, suggesting that swelling was induced by CAAs. At CAA concentrations higher than $0.5 \mu \mathrm{g} / \mathrm{ml}$, lysis of some cystospores was observed.

Cystospores germination. Of the three technical CAAs tested $(0.005$ to $5 \mu \mathrm{g} / \mathrm{ml})$, MPD was significantly $(P<0.05)$ more active than DMM, while DMM was significantly $(P<0.05)$ more active than IPRO in inhibiting cystospore germination. $\mathrm{ED}_{50}$ values (doses at which $50 \%$ of the cystospores did not germinate) were $<0.005,0.037$, and $0.159 \mu \mathrm{g} / \mathrm{ml}$ for MPD, DMM, and IPRO, respectively. Germination was completely abolished (MIC) with MPD at $0.05 \mu \mathrm{g} / \mathrm{ml}$, DMM or IPRO at $0.5 \mu \mathrm{g} / \mathrm{ml}$.

Thirty seconds of vortexing (medium speed) was employed to induce synchronous encystment of motile zoospores. Technical CAAs added $(0.005$ to $5 \mu \mathrm{g} / \mathrm{ml})$ to motile zoospores just before vortexing did not interfere with the immediate encystment of most zoospores (90 and 95\%). CAAs of similar concentrations added 1 min after vortexing, to already encysted zoospores, were as inhibitory to cystospore germination as CAAs added before vortexing. In both, percent germination in water controls ranged between 85 and $93 \%$ and $\mathrm{ED}_{50}$ and $\mathrm{MIC}$ values were similar to those indicated above. DMSO, at concentrations used to dissolve technical CAAs, had no effect on the behavior or the appearance of zoospores or cystospores.

Temperature had no effect on CAAs action. Cystospores that were allowed to germinate for $20 \mathrm{~h}$ in CAAs at 10 or $20^{\circ} \mathrm{C}$ showed a similar dose-dependent inhibition of germination at both temperatures. At both temperatures, percent germination in water or DMSO controls was about $90 \%$.

Time-dependent inhibition of cystospore germination. Cystospores in suspension were applied to depressions on glass slides and formulated CAAs were added either immediately (time zero) or 1 or $2 \mathrm{~h}$ later. Percent germination, germ tube length and morphology of germ tubes were recorded microscopically at $4 \mathrm{~h}$. Results shown in Figure 1 indicate that CAAs were significantly $(P<0.05)$ more inhibitory at $0 \mathrm{~h}$ than at 1 - or 2 -h application. When applied at time zero, an $\mathrm{ED}_{50}$ value (dose at which $50 \%$ of the cystospores did not germinate) of $<0.0005,0.002$, and 0.170 $\mu \mathrm{g} / \mathrm{ml}$ was estimated for MPD, DMM, and IPRO, respectively. MPD applied at time zero (Fig. 1A) was completely inhibitory at $\geq 0.005 \mu \mathrm{g} / \mathrm{ml}$, whereas when applied at $1 \mathrm{~h}$ (when $0.1 \%$ of the cystospores have germinated with a germ tube of about $6 \mu \mathrm{m}$ ) it was completely inhibitory at $5 \mu \mathrm{g} / \mathrm{ml}$ (Fig. 1C). While no germ tubes emerged at $\geq 0.005 \mu \mathrm{g} / \mathrm{ml}$ of MPD at time zero (Fig. 1B), 10 to $20 \%$ of the cystospores (Fig. 1C) did produce short germ tubes (3 to $9 \mu \mathrm{m}$ ) at $1 \mathrm{~h}$ application (Fig. 1D). Cystospores treated with CAAs at $2 \mathrm{~h}$, when about $45 \%$ had germinated with $15 \mu \mathrm{m}$ germ tubes, showed no further germination in MPD, but did so in DMM or IPRO (Fig. 1E). Germ tubes failed to elongate in MPD, but showed limited extension in DMM and IPRO (Fig. 1F). Late application $(1 \mathrm{~h})$ of otherwise inhibitory concentrations of CAAs allowed the cystospores to germinate but caused deformation of the germ tubes, more so with MPD than with DMM or IPRO (data not shown).

In other experiments, cystospores were incubated in MPD or $\mathrm{DMM}$ of 1 to $50 \mu \mathrm{g} / \mathrm{ml}$ for $1 \mathrm{~h}$, thereafter washed with water, and allowed to germinate in water or to infect potato leaves. Such temporary exposures were by far less inhibitory to cystospores (Fig. 2A and B) compared with continuous exposure to CAAs (compare with Fig. 1A and B). Cystospores incubated for $4 \mathrm{~h}$ in MPD or DMM $(5 \mu \mathrm{g} / \mathrm{ml})$ failed to germinate (Fig. 1A) or to infect plant tissue, but incubation of $1 \mathrm{~h}$ enabled them to germinate (Fig. 2A and B) and to cause infection (Fig. 2C). Incubation in $50 \mu \mathrm{g} / \mathrm{ml}$ strongly suppressed germ tube development in MPD but not in DMM (Fig. 2B) and, therefore, was detrimental to infection (Fig. 2C)

Germination of sporangia. Formulated CAAs were strongly inhibitory to direct germination of sporangia. In water, percentage germination ranged between 75 and $88 \%$ and germ tubes lengths ranged between 250 and $350 \mu \mathrm{m}$. CAAs reduced percent germination (Fig. 3), germ tube length, and number of germ tubes emerging from a sporangium (not shown). MPD was significantly $(P<$ 0.05 ) more inhibitory to germination than DMM or IPRO at 0.0005 to $0.05 \mu \mathrm{g} / \mathrm{ml}$. ED $\mathrm{D}_{50}$ values (doses at which $50 \%$ of the sporangia did not germinate) for MPD, DMM, and IPRO were $<0.0005$, 0.0414 , and $0.123 \mu \mathrm{g} / \mathrm{ml}$, respectively. MPD of $0.0005 \mu \mathrm{g} / \mathrm{ml}$ (about $1.2 \mathrm{nM}$ ) reduced percent germination by $95 \%$. The compounds reduce germ tube length in a dose-dependent manner (data not shown). The doses of MPD, DMM, and IPRO required to reduce the mean germ tube length by $50 \%$ were $0.001,0.336$, and 0.115 $\mu \mathrm{g} / \mathrm{ml}$, respectively. The number of germ tubes was reduced from 2 to 3 per sporangium in controls to one or none in treated sporangia. Interestingly, sporangia that failed to directly germinate in CAAs were still able to release zoospores after cold induction, suggesting that CAAs have no direct killing effect on sporangia.

As with cystospores, sporangial germination and infectivity could be restored after removal of CAAs. Sporangia exposed to MPD at $0,2,4,8$, or $16 \mu \mathrm{g} / \mathrm{ml}$ for $1 \mathrm{~h}$ at $20^{\circ} \mathrm{C}$ and thereafter washed with DDW, produced means of $25 \pm 0,25 \pm 0,24 \pm 1$, $22 \pm 2$, and $6 \pm 3$ sporulating lesions per leaf, respectively, at 7 dpi after inoculation of detached potato leaves.

Mycelial growth in vitro. In liquid cultures MPD at $0.063 \mu \mathrm{g} / \mathrm{ml}$ caused $50 \%$ inhibition of mycelial growth (fresh weight). The doses required to reduce the mean radial growth on solid RDA medium amended with technical grade CAAs were 0.011, 0.077, and $0.12 \mu \mathrm{g} / \mathrm{ml}$ for MPD, DMM, and IPRO, respectively. MPD stopped growth at $0.1 \mu \mathrm{g} / \mathrm{ml}$ whereas DMM and IPRO did so at $0.5 \mu \mathrm{g} / \mathrm{ml}$.

The survival of mycelia that have been temporarily exposed to CAAs was measured on RDA. A large difference in survival was recorded among CAAs. Exposure of $30 \mathrm{~min}$ to MPD at $10 \mu \mathrm{g} / \mathrm{ml}$, as against 90 -min exposure to DMM at $100 \mu \mathrm{g} / \mathrm{ml}$ were required to cause $90 \%$ inhibition in mycelia growth. Such exposures to IPRO had no effect on mycelium growth.

Effect on infection. Sporangia were mixed with formulated CAAs of various concentrations and inoculated onto detached leaves of potato. Percentage of sporulating leaf area produced at 7 dpi is presented in Figure 4. MPD was significantly $(P<0.05)$ more suppressive to infection compared with DMM or IPRO at 0.0005 to $0.05 \mu \mathrm{g} / \mathrm{ml}$, while DMM was significantly $(P<0.05)$ 
more suppressive than IPRO at 0.0005 to $0.05 \mu \mathrm{g} / \mathrm{ml}$ (Fig. 4). $\mathrm{ED}_{50}$ values (the doses required to reduce percentage of sporulating leaf area by $50 \%$ ) were $<0.0005,0.082$, and $0.66 \mu \mathrm{g} / \mathrm{ml}$, and complete inhibition of infection occurred at 0.0005, 0.05, and $0.5 \mu \mathrm{g} / \mathrm{ml}$ for MPD, DMM, and IPRO, respectively (Fig. 4).

The control of late blight by CAAs was tested in intact potato and tomato plants. Formulated CAAs were applied to upper leaf surfaces of potted potato or tomato plants and sporangial suspensions were spray-inoculated onto the treated leaf surfaces $4 \mathrm{~h}$ later. $\mathrm{ED}_{50}$ values (the doses required to reduce infected leaf area by $50 \%$ ) in potato were $0.23,0.44$, and $1.29 \mu \mathrm{g} / \mathrm{ml}$ and in tomato $0.78,3.11$, and $4.37 \mu \mathrm{g} / \mathrm{ml}$ for MPD, DMM, and IPRO, respectively. Complete control in potato was seen with MPD at $6.25 \mu \mathrm{g} / \mathrm{ml}$ or DMM or IPRO at $25 \mu \mathrm{g} / \mathrm{ml}$, whereas complete control in tomato was seen with $25 \mu \mathrm{g} / \mathrm{ml}$ with all compounds.

Postinfection activity. Detached leaflets of potato or tomato were drop inoculated with sporangial suspension, and after $24 \mathrm{~h}$ droplets were supplemented with MPD or DMM. In tomato, small necrotic spots appeared beneath the drops, indicating that penetration of the pathogen has taken place. MPD at 10 to $500 \mu \mathrm{g} / \mathrm{ml}$ and $\mathrm{DMM}$ at 1 to $10 \mu \mathrm{g} / \mathrm{ml}$ were significantly $(P<0.05)$ more effective on tomato (Fig. 5B) than on potato (Fig. 5A). DMM was sig- nificantly $(P<0.05)$ more inhibitory than MPD at 10 to $500 \mu \mathrm{g} / \mathrm{ml}$ in potato and at 1 to $500 \mu \mathrm{g} / \mathrm{ml}$ in tomato. With $10 \mu \mathrm{g} / \mathrm{ml}$ of MPD or DMM, sporulation in tomato was inhibited (relative to water control) by 56 and 96\%, respectively (Fig. 5B), as against 27 and $70 \%$ in potato (Fig. 5A). However, both compounds lost their curative efficacy if similarly employed at $48 \mathrm{~h}$ postinoculation (data not shown).

Effect on sporulation. Individual leaflets, each carrying a 3-day-old lesion (about $0.7 \mathrm{~cm}$ diameter) were detached from tomato plants, placed lower surface up on wet filter paper in Nunk dishes, and sprayed with CAAs. The numbers of sporangia produced per leaflet are shown in Figure 6. In water-treated control leaflets, the number of sporangia produced ranged between 24 and $27 \times 10^{3}$ per leaflet. CAAs reduced sporangial counts in a dose-dependent manner with $\mathrm{ED}_{50}$ values (the doses required to reduce sporangial counts by $50 \%$ ) of $63.3,3.7$, and $15.7 \mu \mathrm{g} / \mathrm{ml}$ for MPD, DMM, and IPRO, respectively. In another experiment, droplets of water or CAAs were placed on or around the lesions and sporangial counts were taken after 3 days. In water-treated leaf disks, a mean of $12.3 \pm 0.2 \times 10^{3}$ sporangia per disk was produced. Sporangial yield was significantly $(P<0.05)$ reduced to $8.7 \pm 1.1 \times 10^{3}$ and $3.9 \pm 0.9 \times 10^{3}$ sporangia per disk (inhibition
A

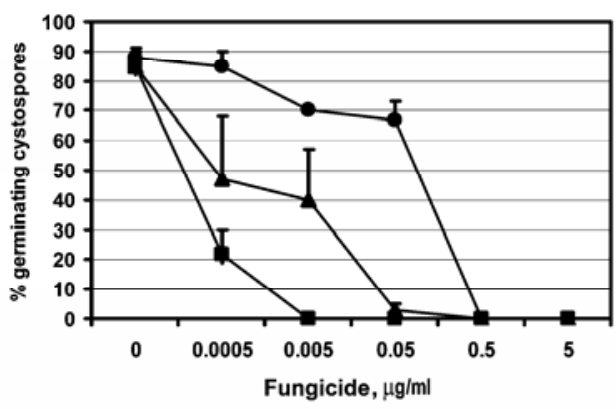

C

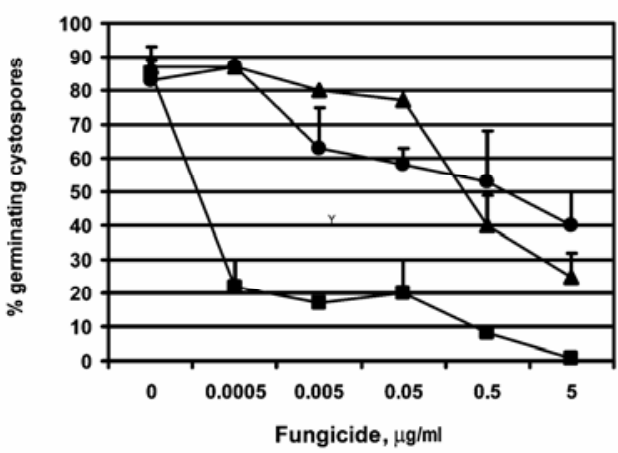

E

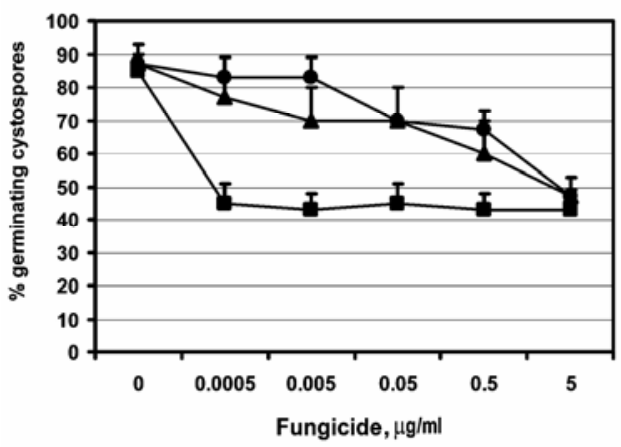

B

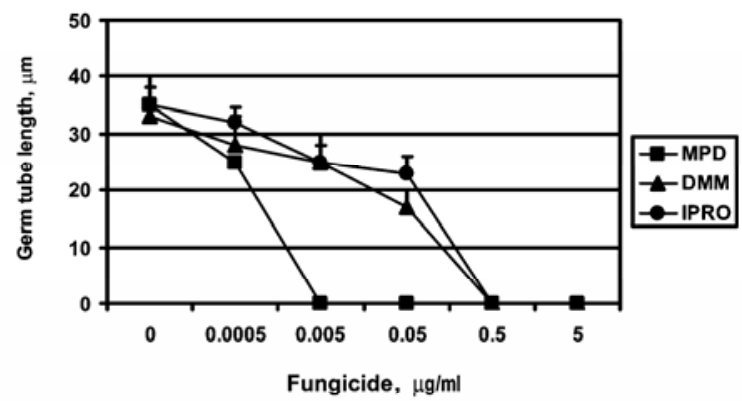

D

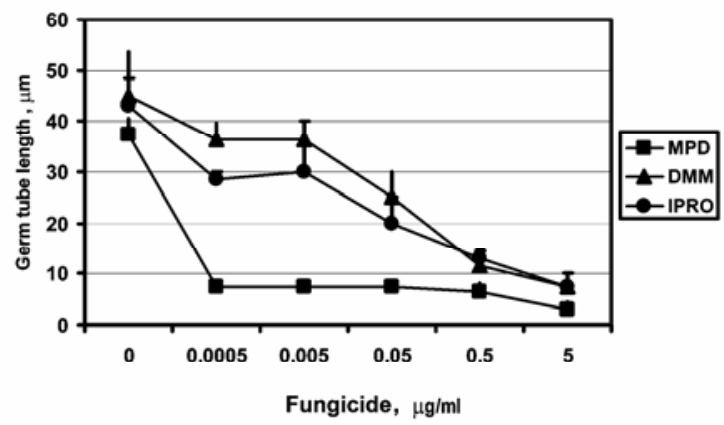

$\mathbf{F}$

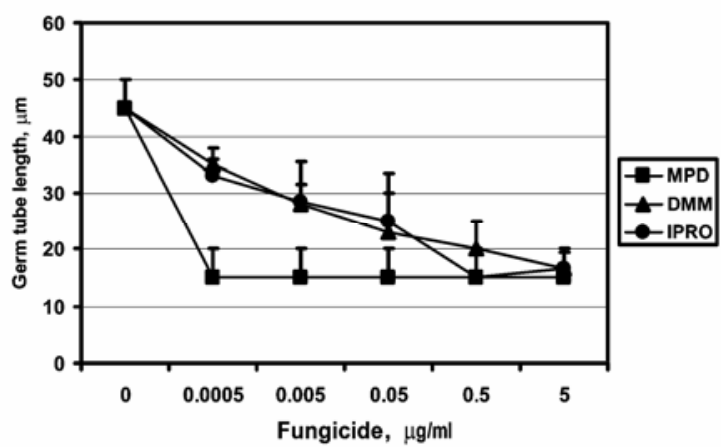

Fig. 1. Effects of timing of carboxylic acid amide (CAA) application on cystospore germination of Phytophthora infestans. Ten microliters of formulated CAAs was added to cystospores at $0(\mathbf{A}, \mathbf{B}), 1(\mathbf{C}, \mathbf{D})$, or $2 \mathrm{~h}(\mathbf{E}, \mathbf{F})$ after germination had started. Germination records were taken after $4 \mathrm{~h}$ of incubation at $20^{\circ} \mathrm{C}$ in the dark. 
of 30 and $76 \%$ relative to water control) in leaf disks treated with MPD and DMM, respectively.

Trans-laminar activity. Results presented in Figure 7 show that MPD had a strong trans-laminar efficacy in both potato (Fig. 7A) and tomato (Fig. 7B), completely abolishing the disease at $250 \mu \mathrm{g} / \mathrm{ml}$. $\mathrm{ED}_{50}$ values (the doses required to reduce leaf area infected by 50\%) for MPD, DMM, and IPRO were 60, 358, and $158 \mu \mathrm{g} / \mathrm{ml}$ in potato and 81,111 , and $218 \mu \mathrm{g} / \mathrm{ml}$ in tomato, respectively. Trans-laminar activities in potato and tomato were
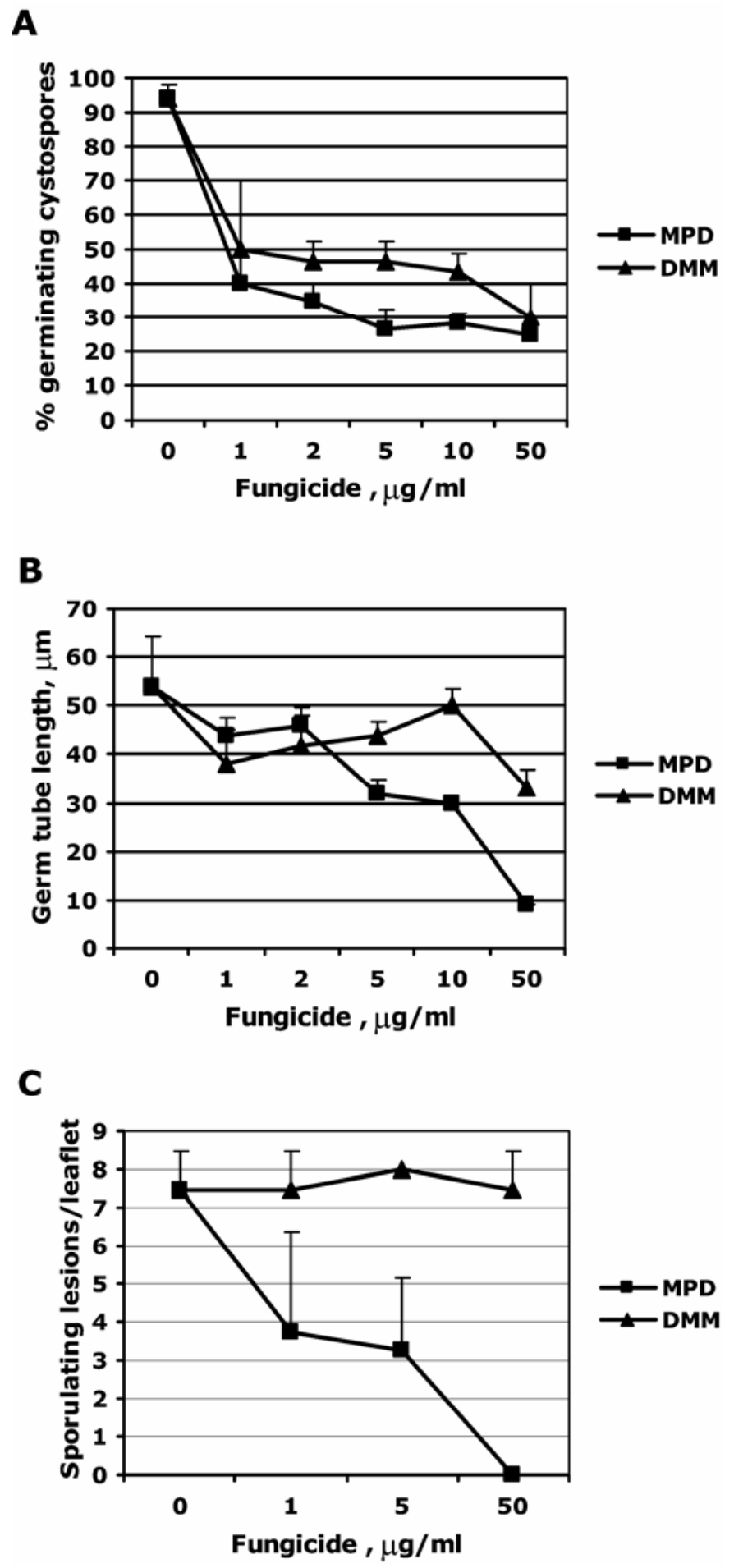

Fig. 2. Temporary exposure for $1 \mathrm{~h}$ of cystospores of Phytophthora infestans to technical mandipropamid (MPD) or dimethomorph (DMM). Treated cystospores were washed with water and allowed $\mathbf{A}$ and $\mathbf{B}$, to germinate at $20^{\circ} \mathrm{C}$ or C, to infect detached potato leaves. Germination records were taken at $5 \mathrm{~h}$ and disease records at 7 days postinoculation. similar except for DMM, which was significantly $(P<0.05)$ more effective in tomato than in potato.

Disease control in shade houses. Figure 8 presents the data collected from two field experiments conducted during December 2005 to March 2006 (Fig. 8A, and C) and December 2006 to March 2007 (Fig. 8B and D). Statistical analysis of these data shows that IPRO and DMM were each significantly $(P=0.05)$ more effective in controlling the disease at increased doses. Control efficacy of MPD, however, was not significantly different among the three doses applied, indicating that the lowest dose was as effective as the two higher doses. MPD was significantly more effective than IPRO or DMM at $75 \mathrm{~g} / \mathrm{ha}$, half of the recommended dose, as well as at the recommended dose of $150 \mathrm{~g} / \mathrm{ha}$, However, at $300 \mathrm{~g} / \mathrm{ha}$, twice the recommended dose, MPD was significantly more effective than IPRO but not more than DMM. DMM was significantly $(P=0.05)$ more effective than IPRO at 150 and $300 \mathrm{~g} / \mathrm{ha}$ but not at $75 \mathrm{~g} / \mathrm{ha}$ (Fig. 8C and D). The calculated doses of each CAA required to inhibit AUDPC by $50 \%$ in each experiment are shown in Table 1 . They were significantly $(P=0.05)$ smaller for MPD compared with DMM or IPRO, and for DMM compared with IPRO.

In the experiment of 2005 to 2006, disease control with MPD persisted 4 weeks after the last spray (Fig. 8A). To confirm this prolonged persistence of MPD, another similar shade-house trial was performed during November 2006 to January 2007 with the potato cv. Nicola, in which CAAs were applied only once at a

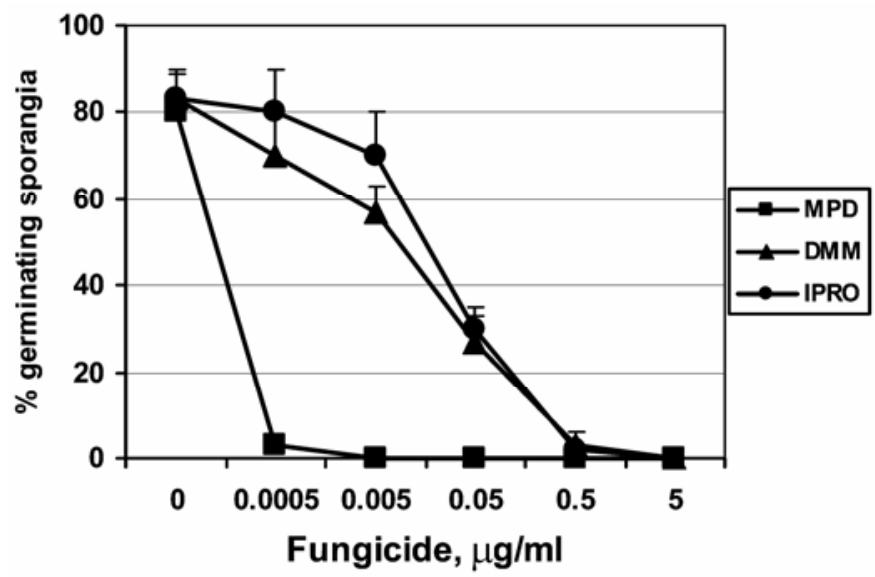

Fig. 3. Germination of sporangia of Phytophthora infestans after carboxylic acid amide (CAA) treatment at $22^{\circ} \mathrm{C}$. Sporangia (no precooling) were mixed with formulated CAAs and percent germination was recorded after $24 \mathrm{~h}$.

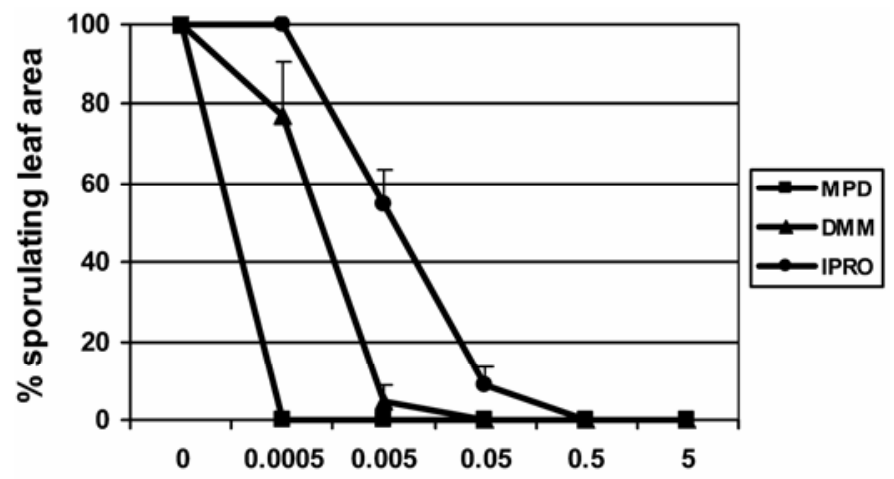

Fungicide, $\mu \mathrm{g} / \mathrm{ml}$

Fig. 4. Efficacy of carboxylic acid amides (CAAs) against infection of detached potato leaves with Phytophthora infestans. Motile zoospores were mixed with formulated CAAs and applied to the lower surface of detached potato leaves. Leaves were incubated in the dark at $20^{\circ} \mathrm{C}$ for $20 \mathrm{~h}$ and then in a growth chamber at $20^{\circ} \mathrm{C}$ with $12 \mathrm{~h} \mathrm{light/day.} \mathrm{Percentage} \mathrm{of} \mathrm{sporulating} \mathrm{leaf}$ area was estimated at 7 days postinoculation (dpi). 
dose of $150 \mathrm{~g} / \mathrm{ha}$. The number of infected leaflets per $10 \mathrm{~m}$ row at 30 dpi in MPD-, DMM-, and IPRO-treated plots was $7.5 \pm 2.9$, $175 \pm 50$ and $550 \pm 41$, respectively, and at $39 \mathrm{dpi}, 10 \pm 4.1$, $725 \pm 126$, and $1,000 \pm 187$, respectively.

Sensitivity to CAAs, overview. Table 1 summarizes the toxicity of CAA fungicides to $P$. infestans at each developmental stage of the life cycle, from spore germination to epidemics in shade houses. Toxicity increased (doses required for $50 \%$ inhibition, $\mathrm{ED}_{50}$ values, decreased) in the following order: cystospore/sporangial germination $>$ infection $>$ mycelium growth $>$ sporulation $>$ zoospores discharge and zoospore encystment. MPD was more toxic compared to DMM or IPRO at all developmental stages except sporulation, while DMM was more toxic than IPRO at all developmental stages except in trans-laminar control efficacy against infection. Epidemics in shade houses were best controlled by MPD and least by IPRO.

\section{DISCUSSION}

The control of $P$. infestans by the CAA fungicides MPD, DMM, and IPRO is documented here for all stages of the asexual life cycle ranging from spore germination to epidemics in the

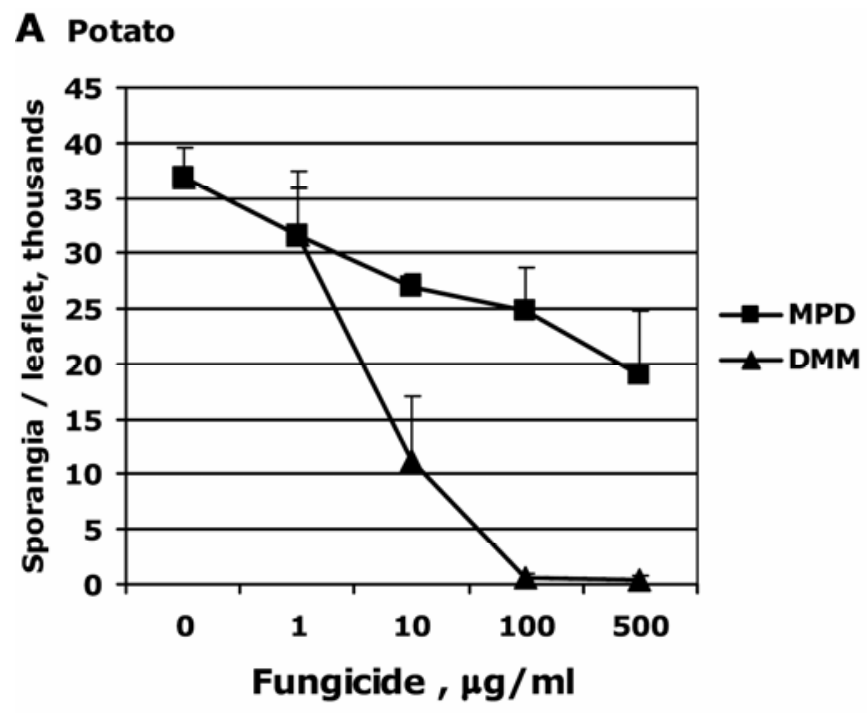

\section{B Tomato}

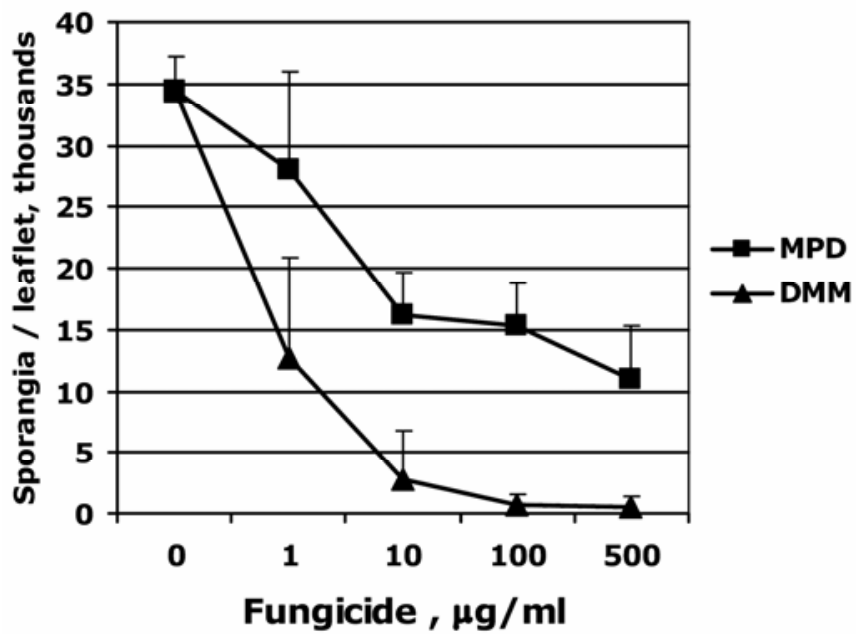

Fig. 5. Postinfection efficacy of carboxylic acid amides (CAAs) against Phytophthora infestans on $\mathbf{A}$, potato and $\mathbf{B}$, tomato. Detached leaflets were treated with CAAs at $24 \mathrm{~h}$ after inoculation. At 4 days postinoculation (dpi) leaflets were placed each in $5 \mathrm{ml}$ of $50 \%$ ethanol and the number of sporangia was counted with the aid of a hemacytometer. field. This is the first comprehensive report on the comparative efficacy of CAA fungicides against $P$. infestans. Recent field results $(8,11)$ show that the new fungicide MPD, (NOA 446510) is effective against late blight in potato and tomato as well as against downy mildews in grapes, vegetables, and tobacco. DMM has been known for several years for its efficacy against these diseases $(1,2,4,16,20)$. IPRO was reported for its efficacy against late blight in tomato and potato and grape downy mildew (12,

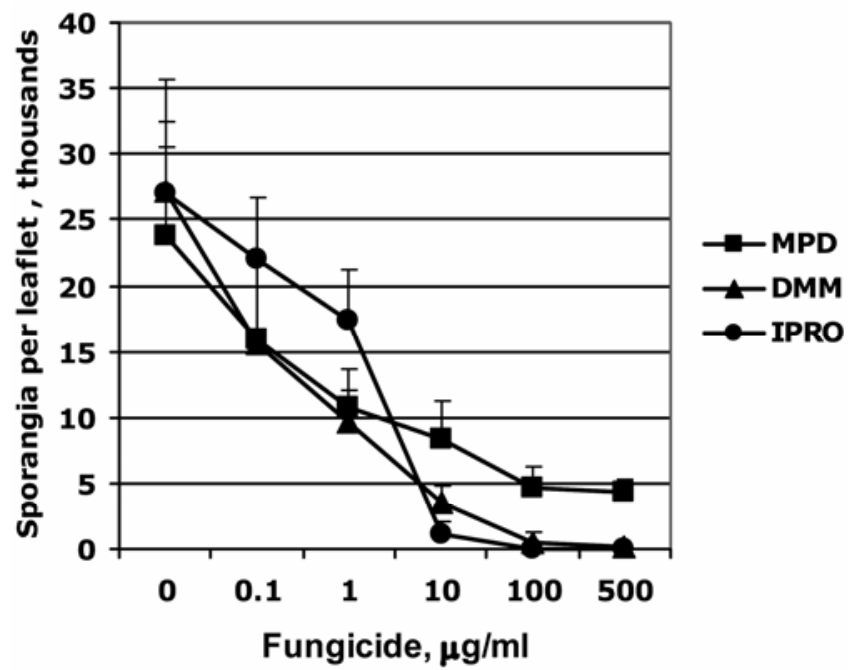

Fig. 6. Effect of carboxylic acid amides (CAAs) on sporulation of Phytophthora infestans in 3-day-old lesions of late blight in tomato. At 3 days postinoculation (dpi), when lesions were about $0.7 \mathrm{~cm}$ in diameter, leaves were detached and sprayed with formulated CAA fungicides. At 2 days after spray treatment, the number of sporangia was counted with the aid of a hemacytometer.

\section{A}

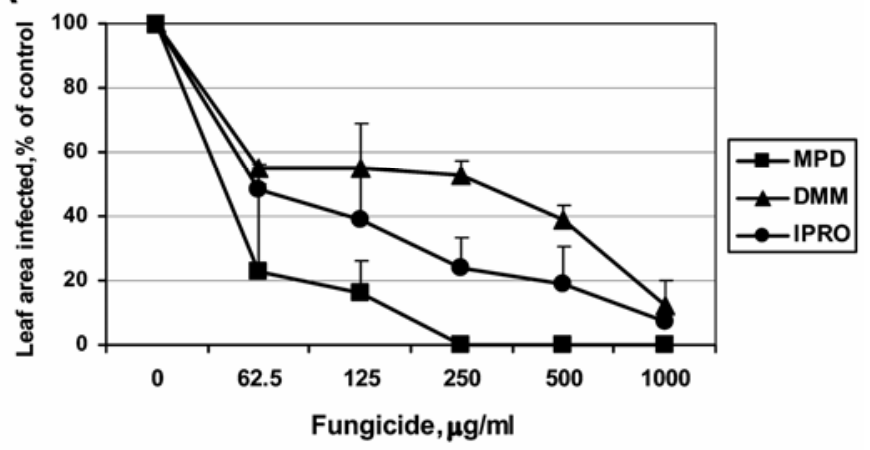

B

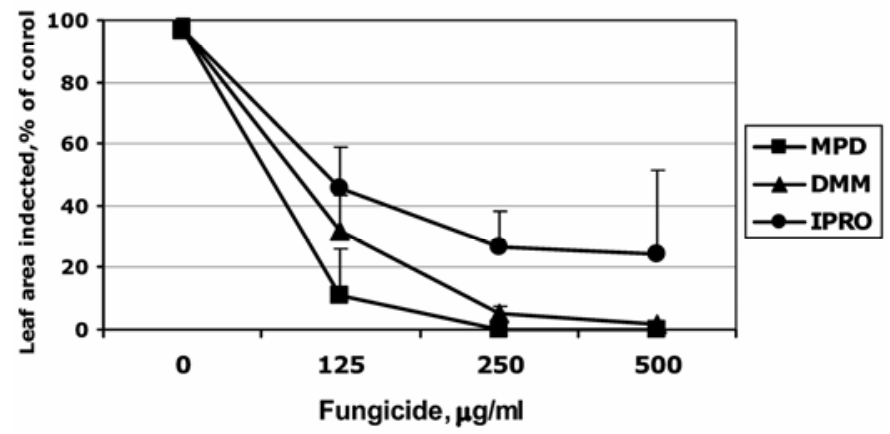

Fig. 7. Trans-laminar activity of carboxylic acid amides (CAAs) against late blight in $\mathbf{A}$, potato and $\mathbf{B}$, tomato. Plants were sprayed with formulated CAAs on upper leaf surfaces, detached after $4 \mathrm{~h}$, and inoculated with sporangial suspension of Phytophthora infestans on their lower leaf surfaces. Percent leaf area occupied by sporulating lesions was assessed at 6 days postinoculation (dpi). 
$13,17,21)$ and its related fungicide benthiavalicarb against grape downy mildew (18). DMM $(2,4,16)$, IPRO $(12,13)$, and MPD (14) were reported to inhibit spore germination and benthiavalicarb was suggested to inhibit the encystment of zoospores (18). Inhibition of cell wall synthesis/assembly $(1,2,13,16)$ was claimed as a possible mechanism of action of DMM and IPRO.

The data presented here suggest a stage-specific action against $P$. infestans of all CAAs tested. They all were highly inhibitory, with significant differences in intrinsic activity, to spore germination (of cystospores and sporangia) and to a lesser extent to germ tube elongation and hyphal growth. None of them affected zoospore discharge from sporangia, zoospore motility or viability, nor the transition of the zoospores to cystospores (encystment) which requires cell wall synthesis or rearrangement. CAAs had no effect on encystment when applied to motile zoospores, regardless of whether the zoospores were vortexed (to synchronize encystment) or not, suggesting that cell wall synthesis or deposition at this stage is not affected. The failure of cystospores to germinate in the presence of CAAs was often associated with their swelling, confirming earlier observations with DMM (2). Electron microscopy studies showed that most of the central part of such cystospores was occupied by a large vacuole (unpublished data), suggesting enhanced water uptake by CAA-treated cell, probably due to the accumulation of unknown osmotica.

The complete failure of cystospores to germinate occurred only when CAAs were added at "time zero" when germination in vitro
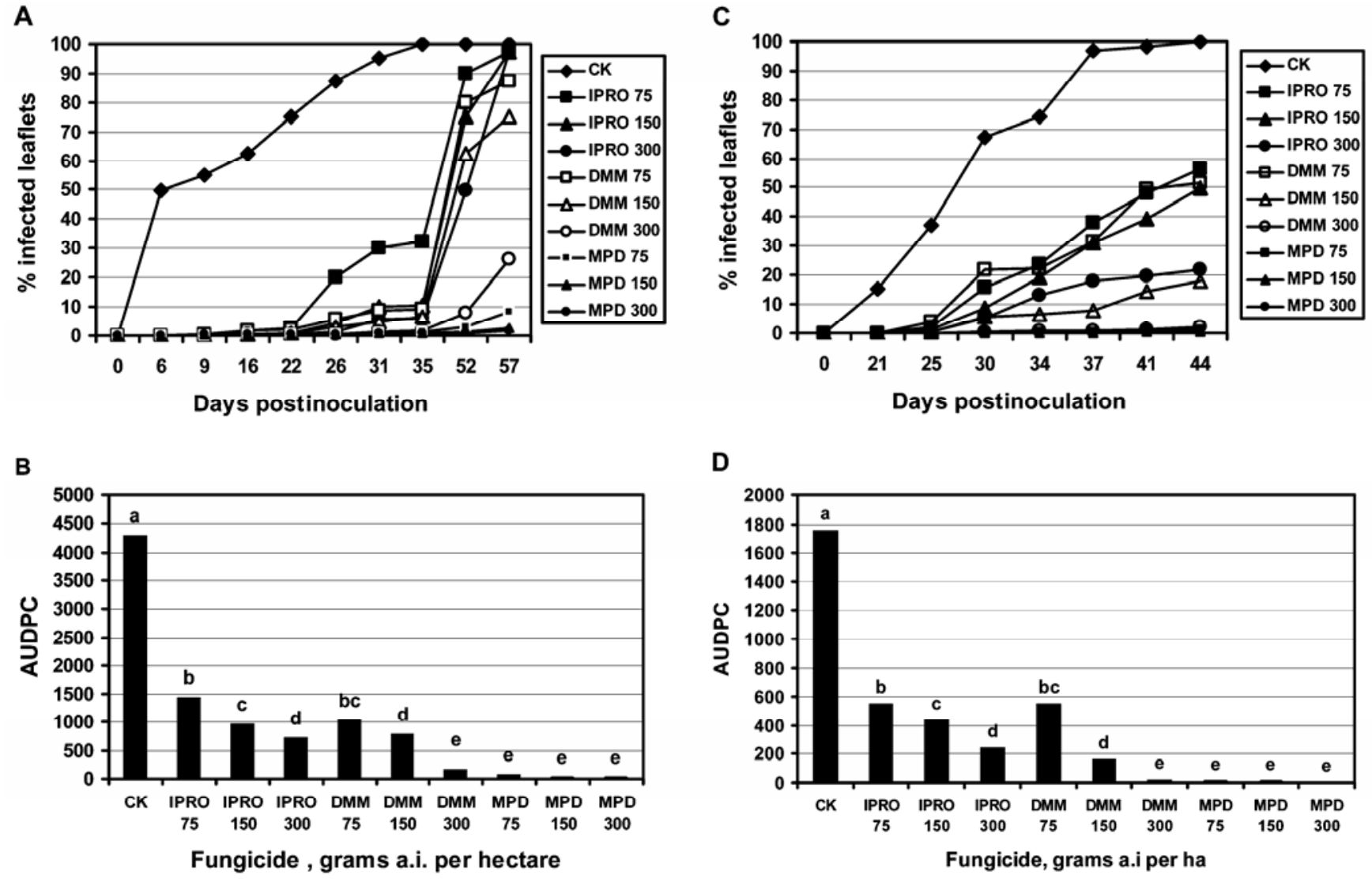

D

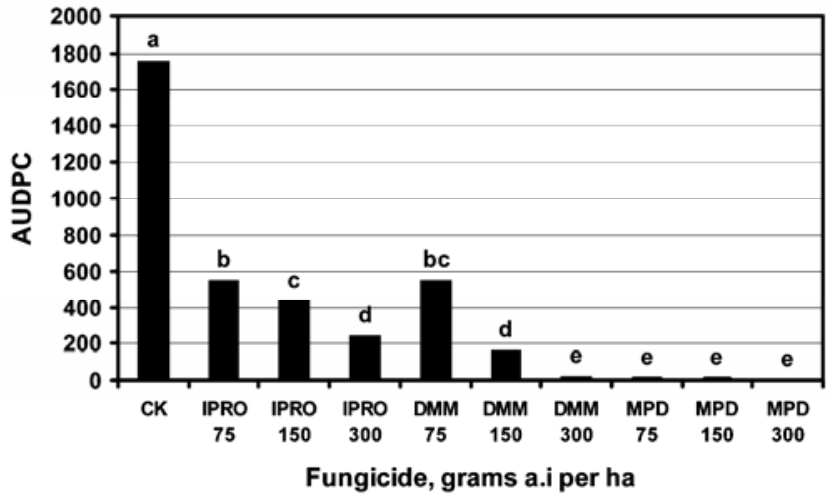

Fig. 8. Efficacy of carboxylic acid amide (CAA) fungicides in controlling late blight in shade house-grown potato. A and $\mathbf{C}$, Disease progress curves in trials conducted in 2005 to 2006 and 2006 to 2007, respectively. B and D, Area under disease progress curves (AUDPC) calculated from data in A and C, respectively. Different letters on columns in $\mathbf{C}$ and $\mathbf{D}$ indicate a significant difference according to Fisher's protected least significant difference (LSD) test $(P=0.05)$.

TABLE 1. Doses of carboxylic acid amide fungicides required for $50 \%$ inhibition of the asexual developmental stages in the life cycle of Phytophthora infestans ${ }^{\mathrm{a}}$

\begin{tabular}{|c|c|c|c|}
\hline Developmental stage & Mandipropamid & Dimethomorph & Iprovalicarb \\
\hline Zoospore release $\left(\mathrm{T}^{\mathrm{b}}, \mathrm{F}^{\mathrm{c}}\right)$ & $>5$ & $>5$ & $>5$ \\
\hline Zoospores encystment (T,F) & $>5$ & $>5$ & $>5$ \\
\hline Cystospore germination (T) & $<0.005$ & 0.037 & 0.159 \\
\hline Sporangial germination $(\mathrm{F})$ & $<0.0005$ & 0.0414 & 0.123 \\
\hline Mycelium growth $(\mathrm{T})$ & 0.011 & 0.077 & 0.120 \\
\hline Infection in detached potato leaves $(\mathrm{F})$ & $<0.0005$ & 0.082 & 0.660 \\
\hline Infection in intact potato plants $(\mathrm{F})$ & 0.23 & 0.44 & 1.29 \\
\hline Trans-laminar efficacy in intact potato plants $(\mathrm{F})$ & 65 & 358 & 158 \\
\hline Trans-laminar efficacy in intact tomato plants $(F)$ & 81 & 111 & 218 \\
\hline Epidemics in potato $(\mathrm{F})^{\mathrm{d}}$ & 40.5 & 73.6 & 98.9 \\
\hline
\end{tabular}

\footnotetext{
${ }^{a}$ Calculated by Probit analysis.

${ }^{\mathrm{b}}$ Technical compounds, $\mu \mathrm{g} / \mathrm{ml}$.

${ }^{\text {c }}$ Formulated compounds, $\mu \mathrm{g} / \mathrm{ml}$.

${ }^{d}$ Formulated compounds, g/ha. Means of 2 years of data.
} 
was initiated. When added $1 \mathrm{~h}$ later (when one out of 1,000 cells have germinated with a short germ tube), about $45 \%$ of the cells did germinate. This suggests that CAAs act within the first hour of the germination process. CAAs did not stop germination of cystospores that have committed germination. Late application of CAAs to cystospores allowed germination but did not allow the germ tubes to normally extend and develop. Applying CAAs to germinating cystospores, at 1 or $2 \mathrm{~h}$ after the start of germination adversely affects the appearance of the germ tubes. Many curled and/or produced swelling at their tip. Some showed ramification and/or shrunk. However, most cystospores retained their initial cell walls with no apparent lysis. Whether one common or several different biochemical reactions are affected during germ tube emergence and germ tube growth remain to be shown.

One hour of incubation in CAAs, of cystospores, sporangia, or mycelia, was not as toxic as was a continuous exposure. After removal of CAAs, cells partially retained the ability to germinate and infect. This might indicate that the binding of CAA to its target is not completed in $1 \mathrm{~h}$ either, because CAA did not reach it, the target is not yet ready for binding, or because the binding is loose. Slow uptake of $\mathrm{C}^{14}$-MPD was observed with leaf tissues (9). Within $1.5 \mathrm{~h}$ after application, 4.9 and $1.3 \%$ of the applied compound reached the mesophyll of potato and grape leaves, respectively.

CAAs differed in their intrinsic activity against germination of cystospores and sporangia and in disease control. Sporangia or cystospores that were mixed with CAAs showed a dose-dependent inhibition of infectivity to potato, similar to that obtained with spore germination in vitro. This suggests that inhibition of infection is a consequence of the inhibition of spore germination on the leaf surface. Knauf-Beiter and Hermann (14) showed such inhibition with MPD. Unlike metalaxyl, in which spore germination proceeds freely and penetration of the pathogen into the leaf produces hypersensitive response- (HR) like symptoms, no such HR-like spots developed after CAA treatment, confirming that penetration of the pathogen does not take place but rather spores fail to germinate.

When applied curatively (postinfection), after penetration of the pathogen into the leaf tissue took place, CAAs were less effective in disease control. Application of CAAs at 1 dpi was partially effective but dropped at 2 dpi. MPD was less active compared with DMM or IPRO when applied curatively, probably because its slower uptake.

While nanomole concentrations of MPD were required for complete inhibition of spore germination and germ tube development, micromole concentrations were required for complete inhibition of colonization and sporulation in planta. This confirms that the amount of MPD taken up by the leaf tissue is not high enough to stop mycelium growth and sporangial production. Indeed, mycelium growth in vitro is shown here to be less sensitive to MPD compared with spore germination (Table 1). Studies with $\mathrm{C}^{14}$-MPD in potato showed (9) that 3 days after application, 54.9, 36.4 , and $8.7 \%$ of the applied radioactive MPD were on the leaf surface (water wash), bound on the surface and in wax (organic solvent wash), and in the leaf extract, respectively.

Of the three CAAs tested, MPD was best performing in translaminar activity. In both potato and tomato, MPD applied to upper leaf surface successfully abolished infection resulting from inoculation of the lower leaf surface, reflecting its high efficacy against spore germination. The small quantities of MPD traveling from the upper to the lower leaf surface are apparently high enough to stop spore germination.

Trials conducted in shade houses showed that at the recommended dose of $150 \mathrm{~g} / \mathrm{ha}$, MPD was best performing, DMM was second best and IPRO was the least effective. The performance in shade houses reflects the differential intrinsic efficacy of the compounds in controlling spore germination (and consequently, infection) as well as the differential trans-laminar activity. Differ- ential rain-fastness of the compounds may have also contributed to their performance, as 100 and $120 \mathrm{~mm}$ of rainfall were accumulated during the epidemics. Seven days after application, $49 \%$ of the $\mathrm{C}^{14}$-MPD applied to potato leaves could be recovered from leaf surface and wax (9). This prolonged binding of MPD to the leaf cuticle, its good rain-fastness (9), and its pronounced trans-laminar mobility may ensure its prolonged availability to lower leaf surfaces. The high sensitivity of $P$. infestans to MPD at the spore germination stage allows the control of late blight by small amounts of MPD even under high disease pressure.

\section{ACKNOWLEDGMENTS}

We thank D. Hermann, F. Huggenberger and G. Knauf-Beiter of Syngenta Crop Protection for critical reading of the manuscript, and K. Ward, Department of Statistics, Syngenta Crop Protection, for aiding with statistical analyses. The technical assistance of E. Rubin, A. Baider, M. Galperin, and E. Brinder of Bar-Ilan University is gratefully acknowledged.

\section{LITERATURE CITED}

1. Albert, G., Curtze, J., and Drandarevski, C. 1988. Dimethomorph (CME 151), a novel curative fungus fungicide. Brighton Crop Protection Conference-Pests and Diseases 17-22.

2. Albert, G., Thomas, A., and Guehne, M. 1991. Fungicidal activity of dimethomorph on different stages in the life cycle of Phytophthora infestans and Plasmopara viticola. ANPP-Third International Conference on Plant Diseases Bordeaux.

3. Cohen, Y. 2002. Populations of Phytophthora infestans in Israel underwent three major genetic changes during 1983 to 2000. Phytopathology 92:300-307.

4. Cohen, Y., Baider, A., and Cohen, B. H. 1995. Dimethomorph activity against oomycete fungal plant pathogens. Phytopathology 85:1500-1506.

5. Gisi, U. 2002. Chemical control of downy mildews. Pages 119-159 in: Advances in Downy Mildew Research. P. T. N. Spencer-Phillips, U. Gisi, and A. Lebeda, eds. Kluwer Academic Publishers, Netherlands.

6. Gisi, U., Waldner, M., Kraus, N., Dubuis, P. H., and Sierotzki, H. 2007. Inheritance of resistance to carboxylic acid amide (CAA) fungicides in Plasmopara viticola. Plant Pathol. 56:199-208.

7. Griffiths, R. G., Dancer, J., O’Neill, E., and Harwood, J. L. 2003. A mandelamide pesticide alters lipid metabolism in Phytophthora infestans. New Phytol. 158:345-353.

8. Harp, T., Cloud, G., Minton, B., and Cochran, A. 2006. Mandipropamid: A new fungicide for control of late blight and downy mildews. (Abstr.) Phytopathology 96(suppl.):S185.

9. Hermann, D., Bartlett, D. W., Fischer, W., and Kempf, H. J. 2005. The behaviour of mandipropamid on and in plants. Pages 87-92 in: Proceedings of the BCPC International Congress Crop Science \& Technology, Glasgow, UK.

10. Huggenberger, F., and Kuhn, P. J. 2006. Biological and physico-chemical properties of mandipropamid, a new fungicide for the control of oomycetes pathogens. (Abstr.) Phytopathology 96(suppl.):S51.

11. Huggenberger, F., Lamberth, C., and Iwanzik, W. 2005. Mandipropamid a new fungicide against Oomycete pathogens. Pages 93-98 in: Proceedings of the BCPC International Congress Crop Science \& Technology, Glasgow, UK.

12. Jende, G., Steiner, U., and Dehne, H.-W. 1999. Effects of iprovalicarb (SZX 0722) on the development of Phytophthora infestans in tomato plants. Pflanzenchutz-Nachr. Bayer 52:49-60.

13. Jende, G., Steiner, U., and Dehne, H.-W. 2001. Microscopical characterization of fungicidal effects on infection structures and cell wall formation of Phytophthora infestans. Pages 83-90 in: Modern Fungicides and Antifungal Compounds. AgroConcept and Verlag, Bonn, Germany.

14. Knauf-Beiter, G., and Hermann, D. 2005. Site of action of mandipropamid in the infection cycle of target fungi. Pages 99-104 in: Proceedings of the BCPC International Congress Crop Science \& Technology, Glasgow, UK.

15. Lamberth, C., Cederbaum, F., Jeanguenat, A., Kempf, H. J., Zeller, M., and Zeun, R. 2006. Synthesis and fungicidal activity of N-2-(3-methoxy4-propagyloxy) phenylethyl amides. Part II: Anti-oomycetic mandelamides. Pest Manage. Sci. 62:446-451.

16. Matheron, M. E., and Porchas, M. 2000. Impact of azoxystrobin, dimethomorph, fluazinam, fosetyl-Al, and metalaxyl on growth, sporulation, and zoospore cyst germination of three Phytophthora spp. Plant Dis. 84:454-458.

17. Mehl, A., and Buchenauer, H. 2001. Investigations of the biochemical 
mode of action of iprovalicarb. Pages 75-82 in: Modern Fungicides and Antifungal Compounds. AgroConcept and Verlag, Bonn, Germany.

18. Reuveni, M. 2003. Activity of the new fungicide benthiavalicarb against Plasmopara viticola and its efficacy in controlling downy mildew in grapevines. Eur. J. Plant Pathol. 109:243-251.

19. Rubin, E., Cohen, Y. 2006. An improved method for infecting tomato leaves or seedlings with oospores of Phytophthora infestans used to investigate F1 progeny. Plant Dis. 90:741-749.

20. Stein, J. M., and Kirk, W. W. 2003. Variations in the sensitivity of
Phytophthora infestans isolates from different genetic backgrounds to dimethomorph. Plant Dis. 87:1283-1289.

21. Stenzel, K., Pontzen, R., Seitz, T., Tiemann, R., and Witzenberger, A. 1998. SZX 722: A novel systemic oomycete fungicide. Brighton Crop Protection Conference 367-374.

22. Young, D. H., Kemmit, G. M., and Owen, J. 2005. A comparative study of XR-539 and other oomycete fungicides: Similarity to dimethomorph and amino acid amides in its mechanism of action. Pages 145-152 in: Modern Fungicides and Antifungal Compounds. BCPC, Alton UK. 